\title{
Design and Development of m-Learning Service Based on 3G Cellular Phones
}

\author{
Kwang Sik Chung ${ }^{*}$ and Jeong Eun Lee ${ }^{* *}$
}

\begin{abstract}
As the knowledge society matures, not only distant, but also off-line universities are trying to provide learners with on-line educational contents. Particularly, high effectiveness of mobile devices for e-Learning has been demonstrated by the university sector, which uses distant learning that is based on blended learning.

In this paper, we analyzed previous m-Learning scenarios and future technology prospects. Based on the proposed m-Learning scenario, we designed cellular phonebased educational contents and service structure, implemented m-Learning system, and analyzed $\mathrm{m}$-Learning service satisfaction. The design principles of the $\mathrm{m}$-Learning service are 1) to provide learners with m-Learning environment with both cellular phones and desktop computers; 2) to serve announcements, discussion boards, Q\&A boards, course materials, and exercises on cellular phones and desktop computers; and 3) to serve learning activities like the reviewing of full lectures, discussions, and writing term papers using desktop computers and cellular phones. The m-Learning service was developed on a cellular phone that supports H.264 codex in $3 G$ communication technology. Some of the functions of the $\mathrm{m}$-Learning design principles are implemented in a $3 G$ cellular phone. The contents of lectures are provided in the forms of video, text, audio, and video with text. One-way educational contents are complemented by exercises (quizzes)
\end{abstract}

Keywords-m-Learning, e-Learning Service Platform, Mobile Education Device, Cellular Phone, 3G Networks, H.264

\section{INTRODUCTION}

m-Learning provides learners with educational contents that are customized for the learners' environments. That is done through the learning tools (devices, networks, etc.) The learners can efficiently utilize learning contents at their own educational environments [1-6]. Thus, mLearning aims at helping learners study whenever and wherever regardless of their time and location. To achieve this aim and prepare the ground for various changes in a future educational environment, a customized and advanced m-Learning model should be suggested and provided for the long-term view on mobile environments and future.

Typically, learners move here and there within their own learning environment and do not se-

※ This work was supported by National Research Foundation of Korea- Grant funded by the Korean Government (National Research Foundation of Korea-2011-371-B00020)

Manuscript received May 21, 2011; accepted July 20, 2012.

Corresponding Author: Kwang Sik Chung

* Corresponding author, Dept. of Computer Science, Korea National Open University, Seoul, Korea (kchung0825@ knou.ac.kr)

** Dept. of Educational technology, Hanyang University, Seoul, Korea(daji3144@hanyang.ac.kr) 
cure sufficient learning time [7-11]. Therefore, there has been a requirement for the development of ubiquitous learning environments and for educational contents and services [7,9,12]. However, there have been no concrete and successful development examples for an efficient $\mathrm{m}$ Learning model that is suitable for a learner's characteristics. Thus, an m-Learning model that is suitable for the needs and requirements of learners should be implemented and served [9]. Also, it should be verified by the $m$-Learning system that we have developed.

In this paper, we developed an m-Learning model that is suitable for distance learning universities, and proposed and implemented an m-Learning system that can be applied to distance learning universities. To overcome the drawbacks of the existing e-Learning, we approached $\mathrm{m}$ Learning issues as not being as an alternative for e-Learning and particularly suggest that the new learning model, which takes the characteristics of a distance learning university into account. Moreover, we carried out a pilot test of the m-Learning system, which targets learners of KNOU (Korea National Open University), as a demonstration model for an introduction of mLearning.

\section{THEORETICAL FRAMEWORK}

$\mathrm{m}$-Learning is a learning environment where instructors and learners can access a learning system via mobile devices and wireless networks [13]. It provides the opportunity to learn from everywhere at any time without someone having to connect to permanent physical cable networks $[6,14,15]$. This can be achieved by using mobile and portable devices such as PDAs, cellular phones, UMPCs (Ultra Mobile PC), smart phones and TPCs (Table PCs) [16-18]. They are able to connect learners with learning systems and educational contents in order to present educational contents and to offer a place to exchange educational information between learners and instructors [19-24]. [25] analyzed m-Learning qualities according to the following four characteristics: first, in an m-Learning environment learners can learn anywhere regardless of their location. Second, learners can access the learning system whatever they want, whenever they request and wherever they are. These characteristics give learners a chance to engage in self-regulated learning. Third, it creates the possibility to enlarge learning resources. It prevents learners from studying within limited learning resources. Fourth, m-Learning gives learners the possibility of learning in a real context. [26] developed a handheld device call the Ambient Horn. It is a good example of m-Learning with Sensor based technologies. The Ambient Horn was designed to receive sounds triggered by fingers according to learners' location. Researchers found that many children used the horn in unanticipated ways to interact with their environments. The Ambient Horn ended up acting as a tool that promoted reflection, interpretation and future exploratory activity. It led the way in augmenting learning.

We can find the example of "m-Learning with educational contents" in "Push-On-Service" [1, $13,19,27-29]$. It was an attempt to use mobile technology in a classroom. It is possible to use multimedia for promoting learners' understanding. The system provides a learner, who wants distance learning services right here and right now, with educational contents [30]. These types and kinds of educational contents are what he/she needs and are decided by the device that he/she has. The Push-On-Service includes search tools, collaboration activity support tools, and interaction tools for communication networks [17]

In a cellular phone based m-Learning environment, the need for mobile devices to be small, 
light, and cheap will cause the device-related constraints of educational contents [31]. Devicerelated constraints include limited resources such as relatively small memory capacity, smaller display size and smaller-sized and limited battery power [31]. Cellular phone users require that the types of educational contents and presentation modes can be changed according to their educational environments and their mobile device's resource limitations. The presentation parameters of a cellular phone include the level of educational contents details, such as full length or summaries of educational contents. Presentation qualities, including resolution, color versus gray scale, and frame rate, and presentation-style elements such as sound effects, screen layout, and visual effects should also be considered also.

We define m-Learning as "Learning with learner mobility in unified physical and logical educational environments with the providing of seamless educational contents providence, and adaptations of educational contents according to the learner's educational environments (educational devices, learner's locations, learner's needs, etc.)." Learners in an m-Learning environment want to have control over different proportions of educational media such as audio, video, animations, graphics, and text, based on a learner's learning context, personal taste, mobile situation, and budget [20,32-36]. The same educational contents could be presented with different media combinations that are suitable for different mobility situations.

\section{M-LEARNING SCENARIO}

\section{1. m-Learning Scenario in a Distance Learning University}

Considerations for developing the scenario are as follows: first, most of the students in the graduate school at Korea National Open University(KNOU) are in their 30's and 40's and they have difficulty in using new media and are afraid of new technologies. Second, courses are delivered through broadcasting and the Internet. Third, the processes for developing and implementing a course have to be simple and clear because a large variety of courses are running simultaneously in the university. Based on these considerations, four m-Learning models were developed for KNOU, including the types of lecture, tutorials, online discussions, and learning guides.

KNOU's m-Learning system is based on the systematic combination of wired Internet and the mobile communication network (CDMA). As learning activities occur through cellular phones, PDAs, and wireless networks as well as wired networks using the Internet and CDMA, KNOU's $\mathrm{m}$-Learning system can diagnose the network connection of learners and then provide customized learning services. Therefore, KNOU's m-Learning system is able to provide the functions for developing and sequencing learner-oriented educational contents so that learners can determine educational contents and the sequence of their learning activities.

Educational contents are delivered through the web and CDMA, and learning activities are conducted through computer-mediated communication. The types of delivery for educational contents can be classified into lectures, tutorials, learning guides, practices, and exercises. Educational contents can be provided as either full-length educational contents or summaries of educational contents. Learning activities for internalizing educational contents and enhancing the understanding of the subject include questions and answers between learners and instructors, online discussions among learners, online quizzes, writing individual reports, conducting team projects, etc. 


\subsection{Learning Services in the KNOU m-Learning Environment}

The flow of overall services for the management of educational contents and learning activity supports are as follows: first, the source educational contents, which are the developed lecture materials, are encoded. Basic educational contents are made from the encoded source educational contents and are managed as basic learning materials. They are also saved in a contents database. For the m-Learning system, the basic learning materials are converted into forms that can be played and run on m-Learning devices (cellular phone or desktop computers). As an alternative, individual educational contents for each m-learning device can be developed and con-

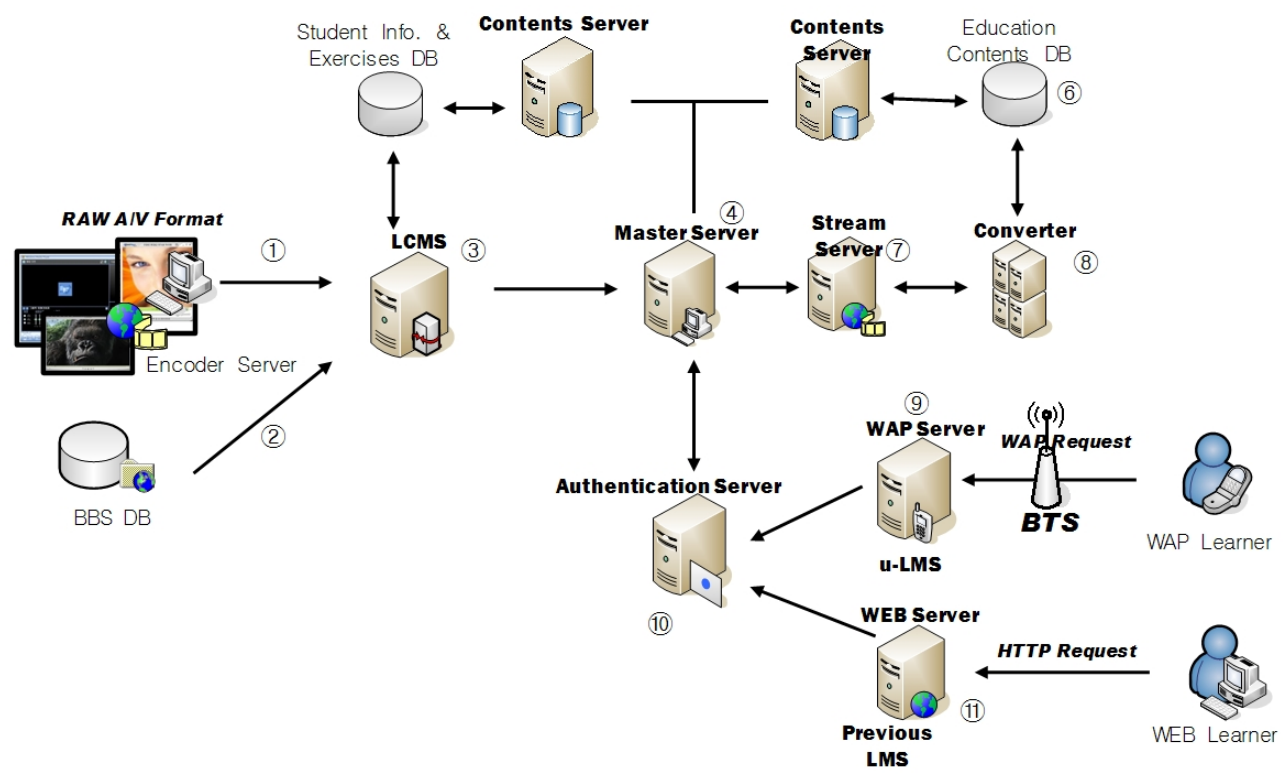

Fig. 1. KNOU's m-Learning Communication Flow

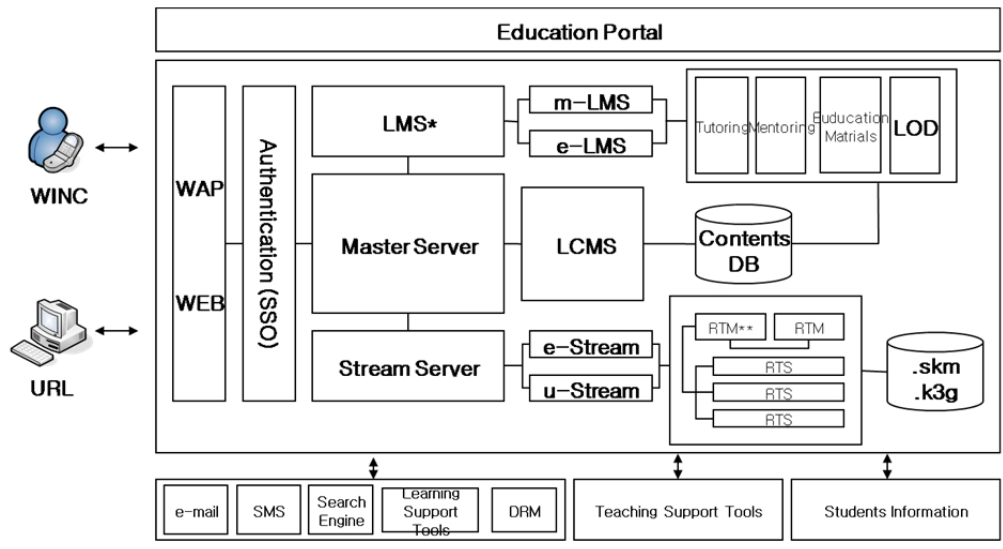

*LMS : Graduate School, Cyber University, Web-class, Life long education

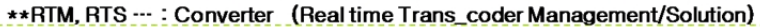

Fig. 2. KNOU's m-Learning System Architecture 
verted according to learning types. Based on these basic educational contents, it is possible to co-operate KNOU's m-Learning system with the existing e-Learning system of KNOU.

In order to use cellular phones as m-Learning device, m-Learning system should be developed with WAP servers. The m-Learning system is composed of three components: master server, converter server, and streaming server. The master server supports educational contents for the existing e-Learning environments. The master server provides educational contents for cellular phones, PDAs, etc.

The converter server takes the responsibility of converting the source educational contents into the basic educational contents that will be suitable for cellular phones. Finally, a streaming server should be furnished for the m-Learning system. Fig. 2 shows a implemented m-Learning system architecture.

\subsection{Educational Contents in an m-Learning Environment}

In KNOU's m-Learning environments, students can learn at their own pace regardless of time and location because there are no limitations $[2,3]$. Educational contents have to be designed and developed according to the results and studies on the diagnostic evaluations and indications $[20,37,38]$. Educational contents adaptation technology could effectively represent educational contents for mobile devices, which were originally built for desktop PCs [11, 27, 39]. Therefore, an m-Learning system and m-Learning contents should have a simple interface and be well formed [40]. They need to have interface consistency between different devices such as cell phones, PDAs, and TPCs. The two kinds of learners (desktop computer learners and cellular phone learners) will study the same educational contents with same ways, but with different devices, in the KNOU m-learning system. The learners can be provided with seamless educational contents on a desktop computer and cellular phone. The educational contents of KNOU's $\mathrm{m}$-Learning system will be designed with the learning object units (time length, media type, size, etc.) [10]. In order to consider the limitations of cellular phones, we deliberately designed a small module. When we decided to define the learning object unit size for KNOU's m-Learning system, we considered the learning characteristics and learner's movement. Due to environmental or surrounding disturbances, learners who study while "on the move" have the tendency to quit more quickly compared to those studying "in a classroom."

The learning object unit in an e-Learning environment is separated by the learning flow or by learning activities that have single learning objects characteristics that are designed by instructors and educational contents developers [41]. However, in an m-Learning environment, educational contents should be separated into a smaller learning object unit that is dependent on the learning context of a learner and on the resource limitations and capability of m-Learning devices [42].

\section{KNOU M -LEARNING SYSTEM}

\section{1 m-Learning Service Schemes and System Architecture}

KNOU's m-Learning system should enable mobile learners to check and read student announcements, discuss issues on the BBS, write an article on the Q\&A board, watch or read the lectures, and do other learning activities including exercises. It should provide mobile learners 


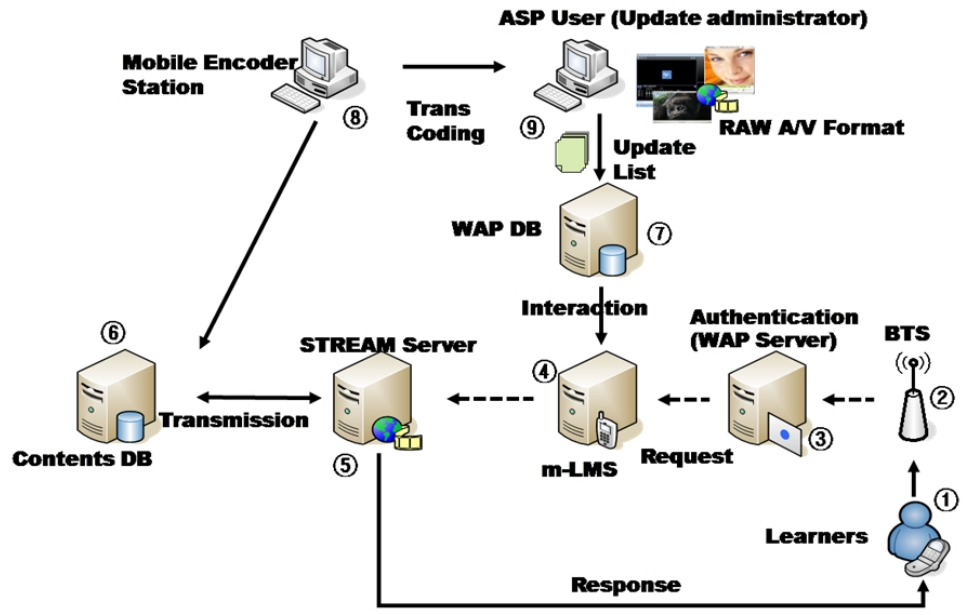

Fig. 3. Service Architecture of KNOU's m-Learning System

with being connected to learning activities including full-length lectures, debates, and assignments. KNOU's m-Learning system was developed based on these principles.

The learners' announcement board, learning guide board (introducing lectures), lecture board (studies, lessons, etc.), exercise and practice board, BBS and Q\&A board were developed based on $3 \mathrm{G}$ cellular phones that support DMB (H.264). Watching lectures were given with text, voice, and video with captures. In order to make up the one-way provision of educational contents, quizzes should be provided on the practice and exercise board. Fig. 3 is the service architecture of KNOU's m-Learning system.

In terms of uploading educational content, a teacher (operator (9) should encode the educational contents using the Mobile Encoder Station (8) so that the contents will be suitable for a mobile phone. The file format should meet the H.264 standard. The teacher (operator) should save the encoded educational contents in the Contents DB (6). Other supplements should be stored in the DB of the server of the WAP, which is connected to the mobile phone by the operator. The WAP server should provide the mobile phone with the following learner's request. In terms of the learner, the educational contents in the WAP are connected to the learner's mobile phone after the learner's enters the WINC number in their mobile phone. The learner requests for service from the WAP server after getting permission from the authentication server through the BTS. Confirmed learners in the WAP server (4) choose various kinds of learning activities and use the video lecture via the stream server.

KNOU's m-Learning system menus consist of the Students Announcement board, Lecture board, watching the lecture, BBS, Learning guide, Quiz \& Practice, etc. The menu functions are as follows:

- Students Announcement Board: Announcements for the mobile learner (Dedicated User of the CMS)

- Lecture Board: Previews and introductions on lectures (introducing lectures as text, short videos, etc.)

- Watching lectures: watching lectures (educational contents) 
- Quiz: Text or AOD or VOD repetition quiz (repeated learning quiz with AOD or VOD or text)

- BBS: Two-way mobile bulletin board; user's questions and comments

- Leaning Guide: Help with the usage of mobile phones

- Introduction: Main subject of the project and learning introduction.

\subsection{Communication Protocols of KNOU's m-Learning System}

In Fig. 4, the flows of messages (communication protocols) between KNOU's m-Learning System and a learner's cellular phone are shown.

(1) A learner connects their cellular phone with SK Telecom's Nate server via a WINC number.

(2) When the "KNOU m-Learning System" button is pushed, then a main introduction page appears on the display of the cellular phone.

(3) After 5 seconds, a learner WAP browser is automatically connected to a Lecture WAP server (LMS).

(4)/(5) A Lecture WAP server provides the main menu page ("learner announcements board," "lecture guide board," etc.) with the learner's cellular phone WAP browser.

(6)/7) When a learner chooses "lecture board" and "lecture number," then the learner's request messages are sent to the Stream server and Contents server.

(8) The educational contents requested by a learner are delivered to the leaner's cellular phone WAP browser.

(9) Requested lectures (educational contents) are played on the learner's cellular phone WAP browser.

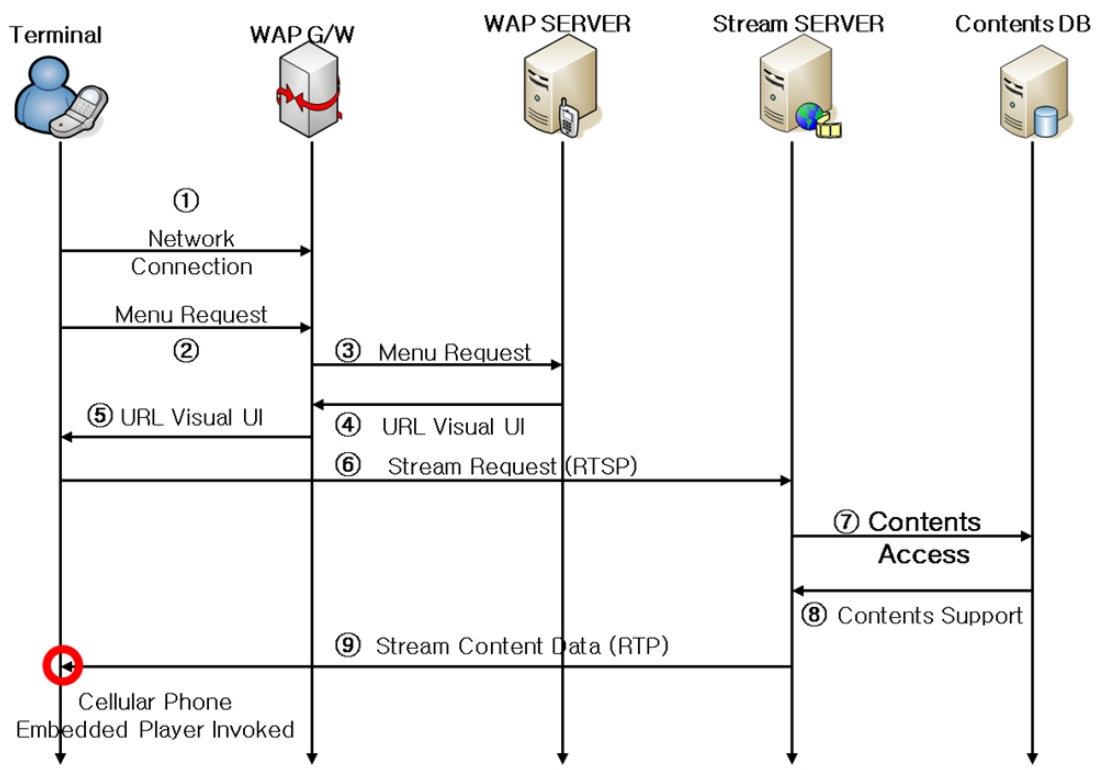

Fig. 4. Protocol flows on KNOU's m-Learning System 


\subsubsection{Leaner access to KNOU's m-Learning system}

When a learner inputs their WINC number and pushes the "Nate button" (xxx\#x Nate, MagicN or ez-i) in order to connect to the Internet and KNOU's m-Learning system, the learner is authenticated and then the main introduction page appears.

A learner is authenticated by a MIN number and the Packet Head number of the cellular phone's User-Agent value. After authentication, the cellular phone number database of a Lecture WAP server is compared with the MIN number and the Packet Head number of the learner's cellular phone as like Fig. 5.

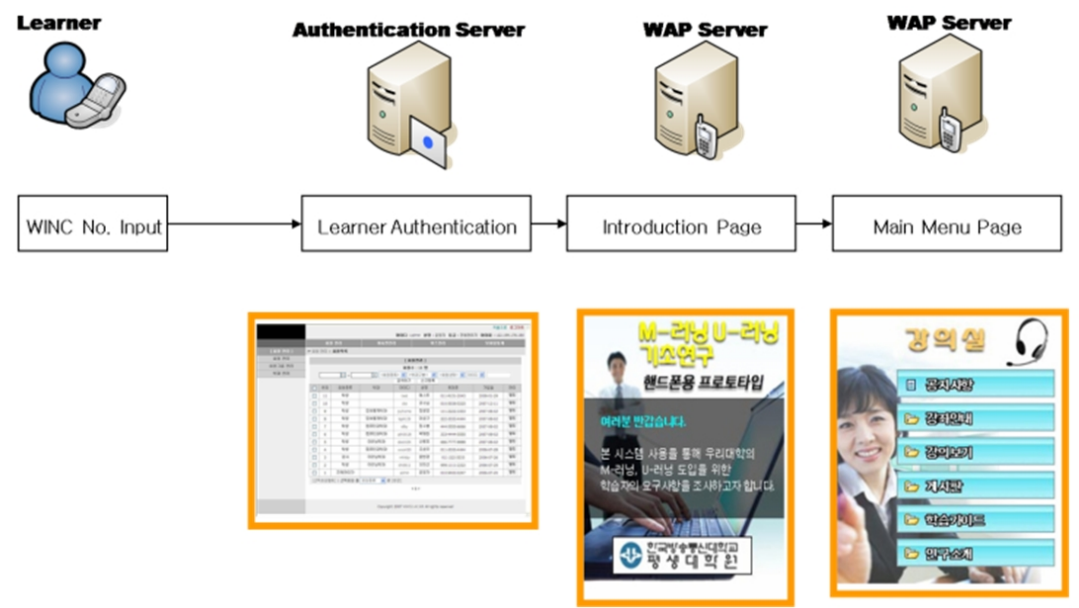

Fig. 5. Interaction Flows for Main Menu Page

\subsubsection{BBS access and Article Uploading}

Instructors and learners can read and write articles in the BBS and on the student announcements board through their desktop computers and cellular phones as like in Fig. 6. Fig. 7 is the BBS board from an instructor's desktop computer on which instructors can write announcements

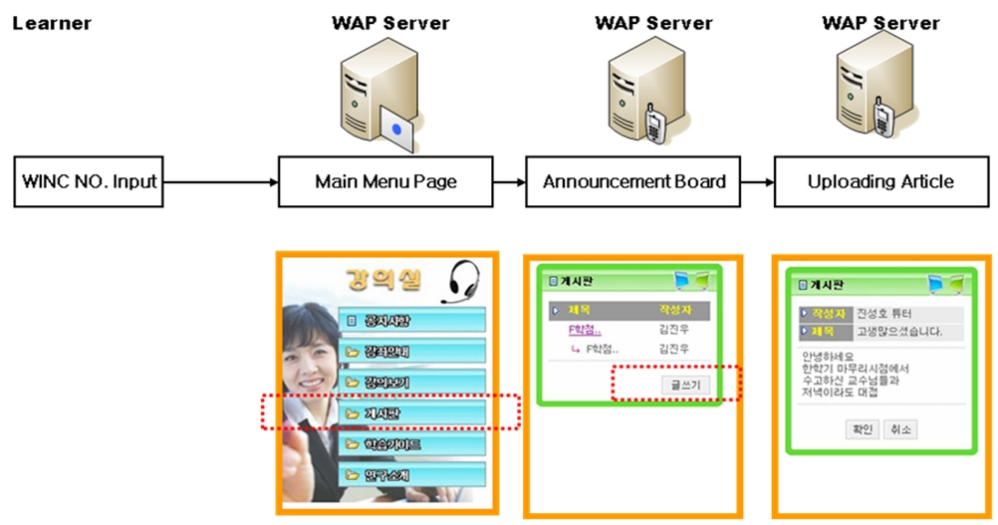

Fig. 6. Menu flows for articles upload on BBS 


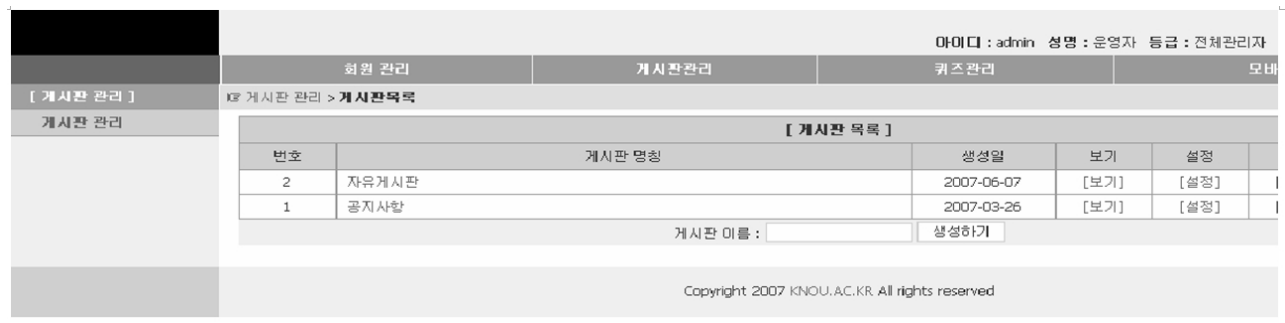

Fig. 7. BBS board of instructor's desktop computer

and replies for learners.

\subsubsection{Watching Lectures}

Learners can select and watch the sub-lectures that they want to see. One sub-lecture unit is independent from each other. The length of a sub-lecture unit is 7-8 minutes and is determined by the section length in the textbook. A one-week lecture consists of 3-4 sub-lectures. Since most learners want to finish one educational content unit within 10 minutes, the length of a sublecture is strategically determined in order for learners to be able to finish one sub-lecture and their exercises within 15 minutes.

Lectures are presented as a video with text or voice and text. Video lectures with text are recorded by instructors and then are encoded in a H.264 format (MPEG-part No.10; QCIF type $12 \mathrm{fps}$ ). Voice lectures are recorded by instructors and then are encoded in a HEACC format. Encoded voice lectures and encoded video lectures can be played with the embedded media player on a learner's cellular phone. Text lectures are developed in the format of WML and are standardized under the KSC5601 standard. Developed text lectures can be played on the WAP browser on a SK-VM (SK-Virtual Machine). A learner's lecture play log is recorded in the database of the Lecture WAP server. If the learner plays the last lecture, the lecture is resumed from the time that the learner stopped the lecture the last time. The lecture play flow is as follows Fig. 9:

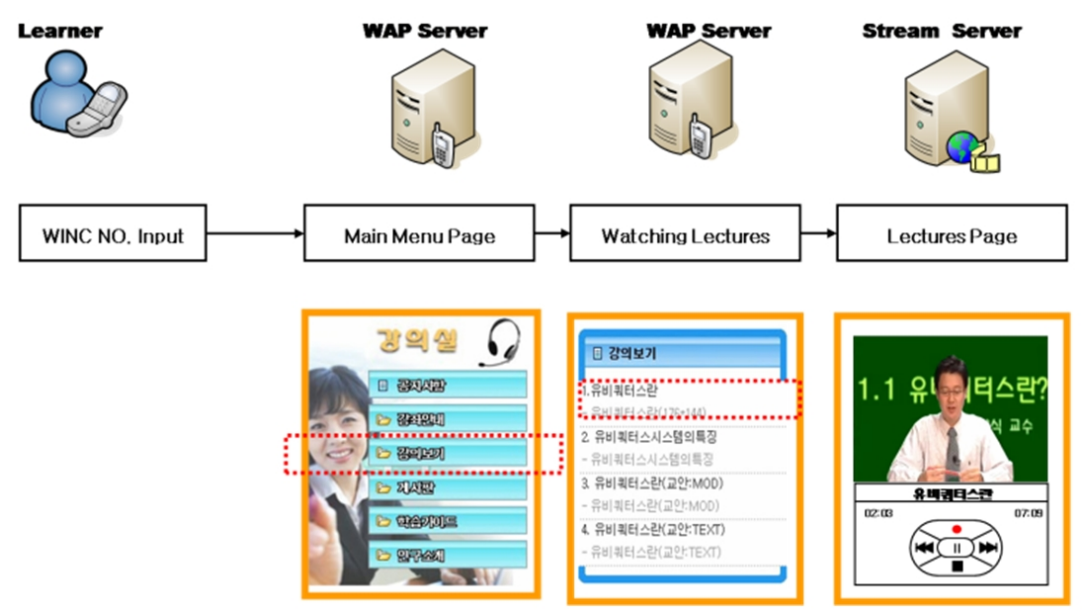

Fig. 8. Menu Flow for Watching Lectures 


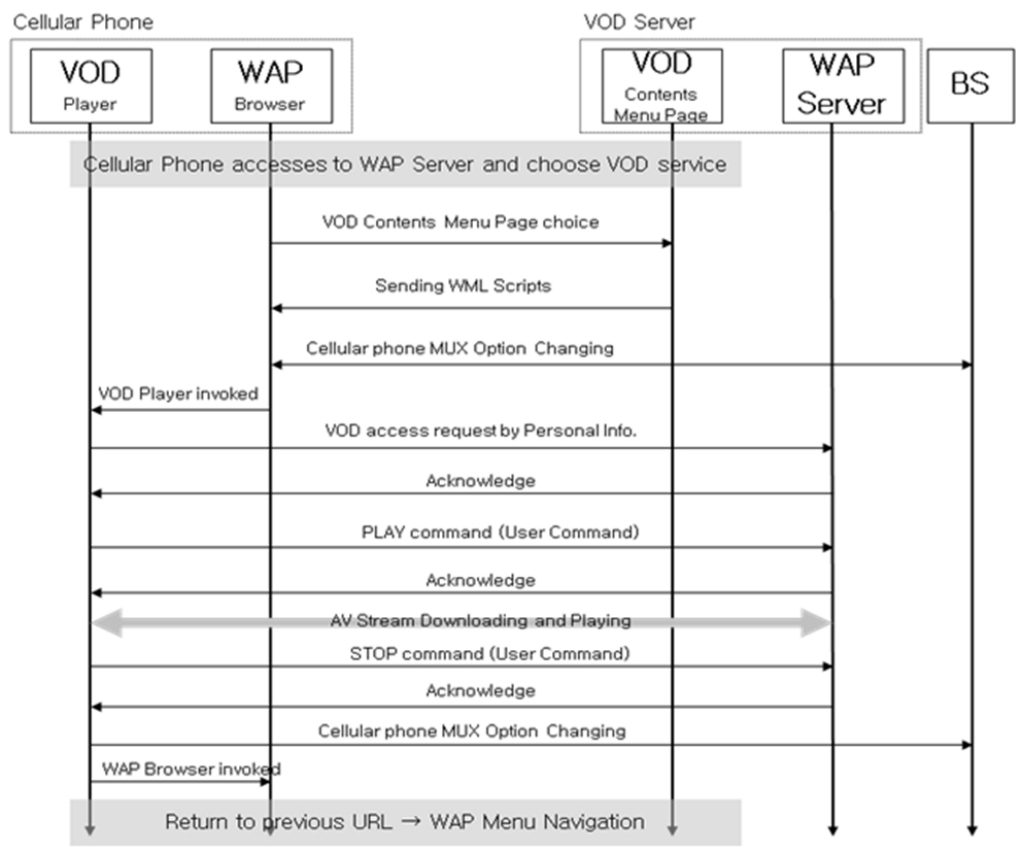

Fig. 9. Session Management for Watching Lectures

(1) A learner connects his WAP browser with the SK Telecom network through a WINC number $(258 \# 0+$ Nate or MagicN or ez-I).

(2) A learner selects the "video lecture menu" to watch a video lecture.

(3) The WML script (contents name, version information, etc.) of a selected video lecture is sent to a cellular phone's WAP browser.

(4) The cellular phone's MUX option is changed in order to connect the learner's WAP browser with the VOD server (streaming server and contents server) by WML script.

(5) The cellular phone's WAP browser starts the cellular phone's embedded media player.

(6) The WML script (contents name, version number, etc.) of the selected video lecture is sent to the VOD server of KNOU's m-Learning system.

(7) Response is an acknowledgement to the request of the cellular phone.

(8) Basic play commands are requested to be executed by a learner.

(9) Response is acknowledgement to the execution request of the cellular phone

(10) A video lecture is played on the embedded media player of a learner's cellular phone.

(11) A stop command is sent to a Lecture WAP server.

(12) Response is an acknowledgement to the stop request doesn't make sense. But it should be "acknowledgement" and not "acknowledge" of the cellular phone.

(13) The cellular phone's MUX option is changed.

(14) The cellular phone's WAP browser is invoked and the main menu page is displayed.

\subsubsection{Exercises}

A learner repeatedly solves exercises, and assesses himself. Through exercises a learner can check his learning level. Exercises consist of multiple-choice questions. A learner selects the 


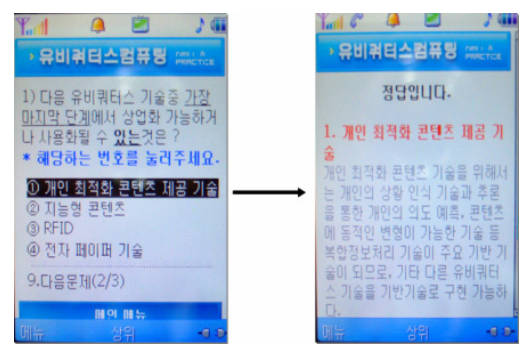

Fig. 10. Exercises Page

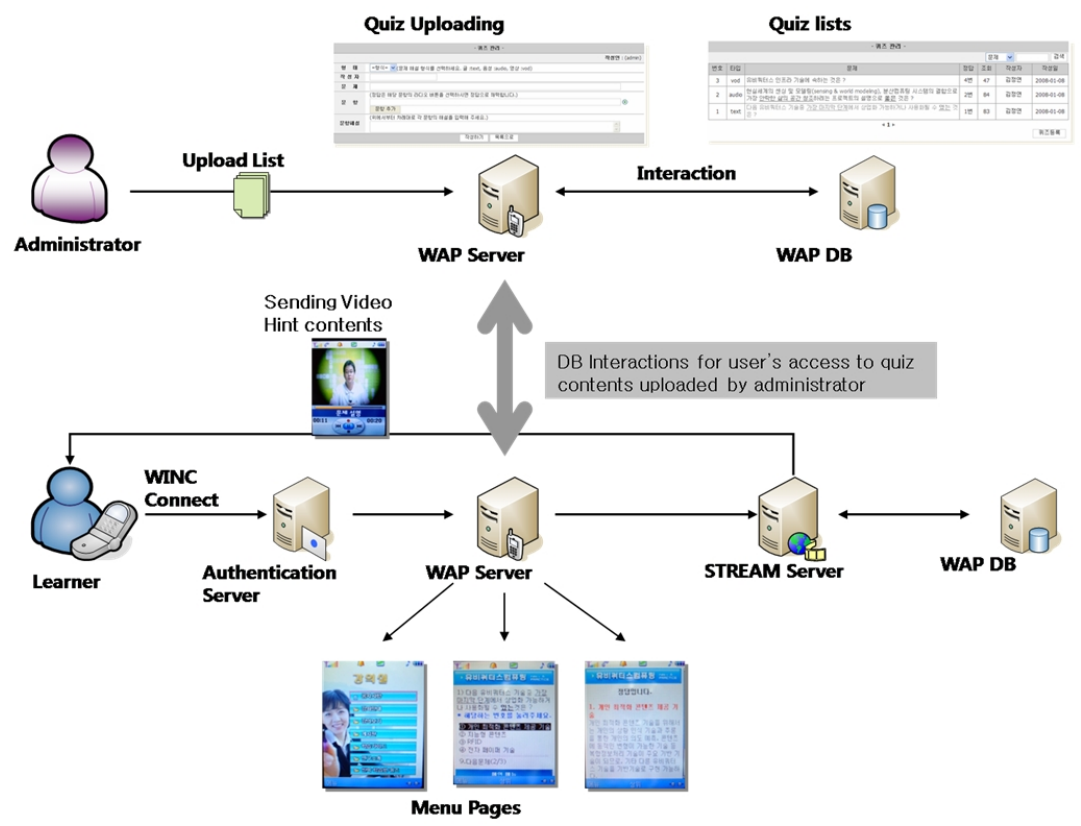

Fig. 11. Management and Access to Exercises

answer to a question and sends their answer to KNOU's m-Learning system. KNOU's mLearning system assesses the learner's answer and sends feedback about the assessment result to the learner. The exercises menu is as shown below.

If a learner's answer is incorrect, then KNOU's m-Learning system sends the correct answer and its explanations. The answer and explanations is a video with voice and text that is developed and edited by instructors. Instructors export answers and explanations to an educational contents database just like they do with lectures. Exercises are developed in the format of WML and are played on a WAP browser.

\subsection{System Platform}

Table 1 shows the software and hardware platform of KNOU's m-Learning system. The proposed m-Learning Server was developed on the IBM Xeon server with Linux OS. It has a WAP server for mobile web service, Stream server for multimedia contents delivery, Authentication 
Table 1. KNOU's m-Learning System Platform

\begin{tabular}{|c|c|c|c|c|c|}
\hline & Service & Type & Specification & OS & Unit \\
\hline \multirow{5}{*}{$\mathrm{H} / \mathrm{W}$} & Stream & Server & Xeon $3.2 \mathrm{Ghz}$ Dual/2G/73G*2 & Linux Redhat 9, Enterprise 3 & 1 \\
\hline & WAP & \multirow{3}{*}{ Server } & \multirow{3}{*}{ Xeon $3.2 \mathrm{Ghz} / 1 \mathrm{G} / 73 \mathrm{G}$} & \multirow{3}{*}{$\begin{array}{c}\text { Linux Redhat 9, Enterprise 3, } \\
\text { Windows NT }\end{array}$} & \multirow{3}{*}{1} \\
\hline & Authentication & & & & \\
\hline & DB & & & & \\
\hline & Contents DB & Storage & NAS/SAN 2Tera & Embedded Station & 1 \\
\hline \multirow{4}{*}{$\mathrm{S} / \mathrm{W}$} & \multicolumn{2}{|l|}{ Storage } & $\begin{array}{l}\text { RTSP/SDP over TCP } \\
\text { RTP/TCP over UDP }\end{array}$ & Linux Redhat 9, Enterprise 3 & 1 \\
\hline & \multicolumn{2}{|c|}{ Encoder } & $\begin{array}{c}\text { Video:H.264, H.263, MPEG4 Visual } \\
\text { Audio:HEAAC, AAC, MP3 }\end{array}$ & Windows XP or higher & 1 \\
\hline & \multicolumn{2}{|c|}{$\begin{array}{c}\text { WAP } \\
\text { (Front-End/Back-End) }\end{array}$} & & $\begin{array}{c}\text { Script : ASP, JSP, PHP etc. } \\
\text { DBMS : MS-SQL, My-SQL, ORACLE }\end{array}$ & \\
\hline & \multicolumn{2}{|c|}{$\begin{array}{c}\text { Authentication Solution } \\
\text { (Back_End) }\end{array}$} & & $\begin{array}{c}\text { Script : ASP, JSP, PHP etc. } \\
\text { DBMS : MS-SQL, My-SQL, ORACLE }\end{array}$ & \\
\hline
\end{tabular}

server for user login management, and a DB server for the storing of a user's activities.

\section{Assessment OF the USABILITY OF KNOU'S M-LEARNING SYSTEM}

The usability assessment was conducted with graduate students of the Department of Computer Science at KNOU for the pilot test of KNOU's m-Learning system. The instrument for the assessment was developed based on the TAM (Technology Acceptance Model) and the attitude theory. The survey items were classified into usefulness, usability, and intent of use. The items consist of the usability and ease of "Watching Lectures," "Practice and Exercises," "Bulletin Board," "Students Announcement board," and satisfaction with the whole system. In addition, survey items for the system requirement and needs of learners were included. The data results were collected through surveys and face-to-face interviews. 17 students out of 20 responded to the survey. Among them, 5 students (29.4\%) were male and 12 (70.6\%) were female. The mean for satisfaction with the all of KNOU's m-Learning system was 3.35 (5 is highest and 1 is lowest), which showed that students were somewhat satisfied with KNOU's m-Learning system in general.

The mean for satisfaction in terms of the ease of using the system was 3.65 out of 5 , which showed that learners were somewhat satisfied with ease of using the system.

Table 2. Satisfaction of learners

\begin{tabular}{|c|c|c|c|c|c|c|c|c|}
\hline \multirow{2}{*}{ Item } & \multicolumn{5}{|c|}{ Frequency } & \multirow{2}{*}{ Mean } & \multirow{2}{*}{ Mode } & \multirow{2}{*}{ SD } \\
\hline & 1 & 2 & 3 & 4 & 5 & & & \\
\hline Satisfaction with the System & 0 & 0 & 11 & 6 & 0 & 3.35 & 3.00 & .49259 \\
\hline
\end{tabular}

Table 3. Satisfaction with the Ease of Usage

\begin{tabular}{c|c|c|c|c|c|c|c|c|c}
\hline \multirow{2}{*}{ Item } & \multicolumn{6}{|c|}{ Frequency } & \multirow{2}{*}{ Mean } & \multirow{2}{*}{ Mode } & \multirow{2}{*}{ SD } \\
\cline { 2 - 9 } & 1 & 2 & 3 & 4 & 5 & & & \\
\hline Ease of Using the System & 0 & 0 & 7 & 9 & 1 & 3.65 & 4.00 & .60634 \\
\hline
\end{tabular}


Table 4. Satisfaction with the Learning Support Function

\begin{tabular}{c|c|c|c|c|c|c|c|c}
\hline \multirow{2}{*}{ Item } & \multicolumn{5}{|c|}{ Frequency } & \multirow{2}{*}{ Mean } & \multirow{2}{*}{ Mode } & \multirow{2}{*}{ SD } \\
\cline { 2 - 8 } & 1 & 2 & 3 & 4 & 5 & & & \\
\hline Learning Support Function & 0 & 1 & 7 & 9 & 0 & 3.47 & 4.00 & .62426 \\
\hline
\end{tabular}

Table 5. Satisfaction of Usefulness

\begin{tabular}{|c|c|c|c|c|c|c|c|c|}
\hline \multirow{2}{*}{ Item } & \multicolumn{5}{|c|}{ Frequency } & \multirow{2}{*}{ Mean } & \multirow{2}{*}{ Mode } & \multirow{2}{*}{ SD } \\
\hline & 1 & 2 & 3 & 4 & 5 & & & \\
\hline Usefulness of the System & 0 & 1 & 4 & 10 & 2 & 3.76 & 4.00 & .75245 \\
\hline
\end{tabular}

The mean for satisfaction in terms of the learning support function of KNOU's m-Learning system was 3.45 out of 5 , which showed that learners were somewhat satisfied with the functions such as "Watching Lectures," "Practice and Exercises," and "Bulletin Board."

The mean for satisfaction in terms of the usefulness of the system was 3.76 out of 5 , which showed that students thought that the functions such as "Watching Lectures," "Practice and Exercises," and the "Bulletin Board" of KNOU's m-Learning system could facilitate their learning. The details of survey results are as explained below.

\subsection{Satisfaction with System Usage}

The mean for satisfaction in terms of the whole system was 3.57, which showed that students were somewhat satisfied with the user interface of the system. The ease of accessing the contents page from a cellular phone was 4.00 , which is the highest satisfaction mean by learners from among the system services survey items. The avoidance of location obstacles was 3.75 . Since KNOU's m-Learning system was developed based on WCDMA, the service stability of the system is 3.0 and learners expressed a low satisfaction with it. If the system is developed based on HSDPA, then video stream buffering problem will be easily solved and we will easily satisfy the requirement of learners' service stability Avoidance of location obstacle is 3.75.

Since KNOU's m-Learning system was developed based on WCDMA, the service stability of the system is 3.0 and learners expressed a low satisfaction with it. If the system is developed based on HSDPA, then video stream buffering problem will be easily solved and we will easily satisfy the requirement of learners' service stability requirements.

Table 6. Satisfaction with System Usage

\begin{tabular}{|c|c|c|c|c|c|c|c|c|}
\hline \multirow{2}{*}{ Item } & \multicolumn{5}{|c|}{ frequency } & \multirow{2}{*}{ Mean } & \multirow{2}{*}{ Mode } & \multirow{2}{*}{ SD } \\
\hline & 1 & 2 & 3 & 4 & 5 & & & \\
\hline easiness of contents page access & 0 & 0 & 3 & 11 & 3 & 4.0 & 4.0 & .61237 \\
\hline Avoidance of location obstacle & 0 & 2 & 4 & 8 & 3 & 3.71 & 4.00 & .91956 \\
\hline service stability & 0 & 7 & 5 & 3 & 2 & 3.00 & 2.00 & 1.060 \\
\hline total average & 0 & 9 & 12 & 22 & 8 & 3.57 & - & - \\
\hline
\end{tabular}

\subsection{Satisfaction with the User Interface}

The mean for satisfaction in terms of the system's user interface was 3.37. The ease of button manipulation was 3.82, which is relatively high. And the ease of page transitions was 3.65 . The ease of display composition and function recognition was 3.65 for both. However, the ease of 
Table 7. Satisfaction with User Interface

\begin{tabular}{|c|c|c|c|c|c|c|c|c|}
\hline \multirow{2}{*}{ Item } & \multicolumn{5}{|c|}{ Frequency } & \multirow{2}{*}{ Mean } & \multirow{2}{*}{ Mode } & \multirow{2}{*}{ SD } \\
\hline & 1 & 2 & 3 & 4 & 5 & & & \\
\hline Ease of Page Transition & 0 & 1 & 5 & 10 & 1 & 3.65 & 4.00 & .70189 \\
\hline Ease of Button Manipulation & 0 & 1 & 2 & 13 & 1 & 3.82 & 4.00 & .63592 \\
\hline Ease of Display Composition and Function Recognition & 0 & 2 & 3 & 11 & 1 & 3.65 & 4.00 & .78591 \\
\hline Ease of menu Selection Recognition & 0 & 2 & 6 & 8 & 1 & 3.47 & 4.00 & .79982 \\
\hline Ease of Menu Position Recognition & 0 & 1 & 7 & 9 & 0 & 3.47 & 4.00 & .62426 \\
\hline Ease of Lecture Contents Recognition & 0 & 3 & 8 & 6 & 0 & 3.18 & 3.00 & .72761 \\
\hline Total Average & 0 & 10 & 31 & 57 & 4 & 3.37 & 4 & .62426 \\
\hline
\end{tabular}

lecture contents recognition was 3.18 , which is relatively low.

We skipped the menus for lecture contents structure and the learner's present contents position in the lecture contents and only showed the lecture contents title, because of the small display size of a cellular phone. We analyzed that the low satisfaction with the ease of lecture contents recognition is due to these reasons. Thus, during the design of mobile educational contents, the contents structure should be considered and the menu display designer should consider the learner's positions meaning of this word here is unclear in the entire educational contents structures and the educational concept maps.

\subsection{Satisfaction of Watching Lectures}

The mean for the satisfaction of watching lectures was analyzed according to the types of lectures (video with text, voice, and text). The mean for the satisfaction with user interface of the whole system was 3.51. The ease of display button manipulation was 3.72 . The ease of educational contents recognition was 3.60 and the usefulness of lecture understanding was 3.33.

A lecture has a video that uses video, voice, and text. The satisfaction with video lectures use text and voice was a little higher than with a text only lecture. The usability of a video lecture with text and voice was 3.75 , and 3.06 for a text only lecture. The ease of lecture contents rec-

Table 8. Satisfaction with Watching Lectures

\begin{tabular}{|c|c|c|c|c|c|c|c|c|}
\hline \multirow{2}{*}{ Item } & \multicolumn{5}{|c|}{ Frequency } & \multirow{2}{*}{ Mean } & \multirow{2}{*}{ Mode } & \multirow{2}{*}{ SD } \\
\hline & 1 & 2 & 3 & 4 & 5 & & & \\
\hline Ease of Educational Contents Recognition & 0 & 4 & 16 & 26 & 4 & 3.60 & 4 & .79982 \\
\hline Ease of Display Button Manipulation & 0 & 3 & 13 & 30 & 5 & 3.72 & 4 & .79982 \\
\hline Usefulness for Understanding Lectures & 0 & 4 & 13 & 30 & 4 & 3.33 & 4 & .79982 \\
\hline Propriety of Lecture Length & 0 & 6 & 14 & 31 & 0 & 3.49 & 4 & .79982 \\
\hline Total Average & 0 & 17 & 56 & 117 & 13 & 3.51 & 4 & \\
\hline
\end{tabular}

Table 9. Satisfaction with Lectures

\begin{tabular}{l|c|c|c}
\hline & Video Lecture & Voice Lecture & Text Lecture \\
\hline Ease of Lecture Contents Recognition & 3.65 & 3.69 & 3.47 \\
\hline Ease of Button Manipulation & 3.88 & 3.88 & 3.41 \\
\hline Usefulness for Understanding Lectures & 3.94 & 3.82 & 2.24 \\
\hline Propriety of Lecture Length & 3.65 & 3.71 & 3.12 \\
\hline Total Average & 3.78 & 3.78 & 3.06 \\
\hline
\end{tabular}


ognition, ease of button manipulation, and the propriety of the length of a video lecture with text and a voice lecture were very similar with each other. However, the usefulness for understanding a video lecture with text was 3.94, which was higher than for a voice lecture.

\subsection{Satisfaction with Exercises}

The mean for the usage satisfaction of exercises was 3.65. The ease of answer choice, ease of exercise recognition, ease of button manipulation, and the propriety of movement between exercise problems was 4.0, 3.71, 3.88, and 3.65 respectively. However, the ease of changing an answer and recognizing question and answer pair was 3.35 and 3.35 respectively. These problems result from the limitations of the display size of a cellular phone and from the separated display of questions and answers. These constraints should be considered when designing a display structure. The satisfaction with summary exercises was 3.71 .

Table 10. Satisfaction with Exercises

\begin{tabular}{|c|c|c|c|c|c|c|c|c|}
\hline \multirow{2}{*}{ Item } & \multicolumn{5}{|c|}{ Frequency } & \multirow{2}{*}{ Mean } & \multirow{2}{*}{ Mode } & \multirow{2}{*}{ SD } \\
\hline & 1 & 2 & 3 & 4 & 5 & & & \\
\hline Ease of Exercise Recognition & 0 & 0 & 6 & 10 & 1 & 3.71 & 4.00 & .58787 \\
\hline Ease of Button Manipulation & 0 & 0 & 3 & 13 & 1 & 3.88 & 4.00 & .48507 \\
\hline Ease of Answer Choice & 0 & 0 & 4 & 8 & 4 & 4.00 & 4.00 & .73030 \\
\hline Ease of Changing an Answer & 0 & 4 & 5 & 6 & 2 & 3.35 & 4.00 & .99632 \\
\hline Recognition of a Question and Answer Pair & 0 & 2 & 8 & 6 & 1 & 3.35 & 3.00 & .78591 \\
\hline Propriety of Movement Between Exercise Problems & 0 & 2 & 3 & 11 & 1 & 3.65 & 4.00 & .78591 \\
\hline Satisfaction with Summary Exercises & 0 & 1 & 5 & 9 & 2 & 3.71 & 4.00 & .77174 \\
\hline Total Average & 0 & 9 & 34 & 63 & 12 & 3.66 & 4 & \\
\hline
\end{tabular}

\subsection{Satisfaction with the BBS board}

The mean for the usage satisfaction of the BBS board was 2.89. The mean for the usage satisfaction of new article uploads and reply uploads was 2.44 and 2.40 respectively. These low numbers result from the limitations related to the display size and small keypad of a cellular

Table 11. Satisfaction with the BBS Board

\begin{tabular}{|c|c|c|c|c|c|c|c|c|}
\hline \multirow{2}{*}{ Item } & \multicolumn{5}{|c|}{ Frequency } & \multirow{2}{*}{ Mean } & \multirow{2}{*}{ Mode } & \multirow{2}{*}{ SD } \\
\hline & 1 & 2 & 3 & 4 & 5 & & & \\
\hline Ease of Article Lists Choice & 1 & 3 & 5 & 7 & 1 & 3.24 & 4.00 & 1.03256 \\
\hline Ease of Articles Legibility & 1 & 3 & 4 & 8 & 1 & 3.29 & 4.00 & 1.04670 \\
\hline Ease of Writing New Articles & 1 & 2 & 6 & 7 & 1 & 2.44 & 3.00 & .81394 \\
\hline Ease of Articles Choice & 2 & 6 & 6 & 1 & 1 & 2.56 & 2.00 & 1.03078 \\
\hline Ease of Writing Reply & 1 & 8 & 5 & 1 & 0 & 2.40 & 2.00 & .73679 \\
\hline $\begin{array}{l}\text { Ease of Classification of Learner's Articles and } \\
\text { Instructor's Articles }\end{array}$ & 1 & 5 & 9 & 1 & 0 & 2.63 & 3.00 & .71880 \\
\hline Eeae of Article Lists Transition & 0 & 1 & 4 & 8 & 3 & 2.81 & 3.00 & .83417 \\
\hline easiness of articles transit & 1 & 3 & 9 & 3 & 0 & 2.88 & 3.00 & .80623 \\
\hline usage of instant interaction & 0 & 3 & 8 & 4 & 1 & 3.19 & 3.00 & .83417 \\
\hline $\begin{array}{l}\text { usage of interaction promotion between instructors } \\
\text { and learners }\end{array}$ & 0 & 3 & 4 & 8 & 1 & 3.44 & 4.00 & .89209 \\
\hline Total Average & 8 & 37 & 60 & 48 & 9 & 2.89 & 4 & \\
\hline
\end{tabular}


phone. Most of students are poor at using the small keypad of a cellular phone and dislike typing on it.

\subsection{Satisfaction with the Students Announcement Board}

The mean for the usage satisfaction of student announcements (ease of checking for quick announcements) was 3.65. The real-time student announcements reading function is the most useful advantage compared with the previous e-learning system.

Table 12. Satisfaction with the Student Announcement Board

\begin{tabular}{c|c|c|c|c|c|c|c|c}
\hline \multirow{2}{*}{ Item } & \multicolumn{5}{|c|}{ Frequency } & \multirow{2}{*}{ Mean } & \multirow{2}{*}{ Mode } & \multirow{2}{*}{ 'SD } \\
\cline { 2 - 9 } & 1 & 2 & 3 & 4 & 5 & & & \\
\hline Ease of Reading Student Announcements & 0 & 2 & 3 & 11 & 1 & 3.65 & 4.00 & .78591 \\
\hline
\end{tabular}

\section{CONCLUSION}

The purpose of this study was to develop an m-Learning scenario, to implement an mLearning system, and to analyze the satisfaction with the system. First of all, we defined an mLearning scenario and m-Learning model. We also considered the applicability of mobile technology and devices (cellular phones and PDAs with WCDMA). We developed KNOU's mLearning system with $3 \mathrm{G}$ cellular phones and desktop computers. The same service and educational contents were provided to learners on $3 \mathrm{G}$ cellular phones and wired desktop computers. On KNOU's m-Learning system, instructors and students can seamlessly access educational contents with both their cellular phones and desktop computers. KNOU's m-Learning system was tested as a learning support tool combined with KNOU's e-Learning system. We tested the usability and satisfaction with the service on students. The contributions of this paper are summarized as follows:

- Analyzing and examining technical trends and future technical directions in a mobile media environment

- Defining an m-Learning scenario and m-Learning model

- Developing m-Learning based on cellular phones and desktop computers.

In the future, we need to study the following topics and issues in order to enhance m-Learning services and systems: first, we need a case study of developing mobile contents. If there are no cases, we can refer educational contents and learning objects. Second, we need to predict the technical trends for the m-Learning service and m-Learning system. Third, we need to facilitate the interdisciplinary collaboration between experts in information technology and experts in educational technology. We can then define the m-Learning model. Finally, we need to study the method to integrate the m-Learning service to a real e-Learning system [13].

\section{REFERENCES}

[1] K. S. Chung and K. Son, "Design and development of arithmetic operating learning management system based on PDA," Journal of Korea Association of Computer Education, Vol.12, No.3, 2009. 
[2] S. M. Jung, et al., "Understanding about u-leaning," issue report, KERIS, 2005.

[3] M. Hooft and K. Swan, Ubiquitous computing in education: Invisible technology, visible impact, Lawrence Erlbaum Associates, 2007.

[4] J. Attewell, "Mobile technologies and learning," London: Learning and Skills Development Agency, 2005.

[5] I. Lee, "Ubiquitous computing for mobile learning," Asia-Pacific Cyber education Journal, Vol.2, No.1, 2006, pp.17-28.

[6] Georgiev, et al., "M-learning-a new stage of e-Learning," Citeseer, 2004.

[7] J. E. Lee, et al., "Learner profile model of m-Learning as an adapted system," Proc. International Conference for Media in Education(IcoMe), 2008, pp.196-203.

[8] J. Attewell and C. Savill-Smith, "Mobile learning and social inclusion: focusing on learners and learning," Learning with Mobile Devices, 2003, pp.3.

[9] S. Bull, et al., "Roles for mobile learner models," Proc. IEEE International Workshop on Wireless and Mobile Technologies in Education (WMTE 2004), IEEE Computer Society, Silver Spring, MD., 2004, pp.124-128.

[10] A. Syvanen, M. Pehkonen, H. Turunen, J. Attewell, C. Savill-smith, "Fragmentation in mobile learning," Learning with Mobile Devices, 2004, pp.155-175.

[11] D. Tatar, et al., "Handhelds go to school: Lessons learned," Computer, 2003, pp.30-37.

[12] S. Bull, "User modeling and mobile learning," Proc. User Modeling 2003: 9th International Conference Springer-Verlag, 2003, pp.383-387.

[13] K. S. Chung, et al., "Development and implement of m-Leaning service prototype," Proc. Of Asian Association of Open University(AAOU), 2008, pp.231.

[14] M. Prensky, "What can you learn from a cell phone?," 2005; http://www.innovateon-line.info.

[15] D. Kim, An empirical study on the critical factors for successful m-Learning implementation, Yonsei University, 2005.

[16] M. Weiser, "Ubiquitous computing," IEEE Computer, Vol.26, No.10, 1993, pp.71-72.

[17] L. Naismith, et. al., "Literature review in mobile technologies and learning," FutureLab Report, Vol.11, 2004.

[18] ETNEWS, White book of ubiquitous, 2005.

[19] A. Trifonova, "Mobile learning-review of the literature," Technology Report No.DIT-03-009. University of Trento, Department of Information and Communication Technology, 2003.

[20] M. Ahomeme, et al., Mobile learning and evaluation. Digital learning 2 project working paper, University of Tampere: Hypermedia Laboratory, 2004.

[21] C. Chang and J. Sheu, "Design and implementation of ad hoc classroom and eSchoolbag systems for ubiquitous learning," 2002, pp.29-30.

[22] C. Chang, et al., "Concept and design of Ad Hoc and Mobile classrooms," Journal of Computer Assisted Learning, Vol.19, No.3, 2003, pp.336-346.

[23] H. P. Chang, et al., "An Adaptive Caching Strategy for m-Learning Based on SCORM Sequencing and Navigation," World Wide Web, vol.11, no.3, 2008, pp 397-406.

[24] G. D. Chen, et al., "Ubiquitous learning website: Scaffold learners by mobile devices with information-aware techniques," Computers \& education, Vol.50, No.1, 2008, pp.77-91.

[25] S. Gong, A study of teaching-learning model in m-Learning environment, Gyeogin National University of Education, 2005.

[26] C. Randell, et al., "The Ambient Horn: Designing a novel audio-based learning experience,” Personal and Ubiquitous Computing, Vol.8, No.3, 2004, pp.177-183.

[27] J. Zhang, "Hybrid Learning and Ubiquitous Learning," Proc. ICHL 2008, 2008, pp.250-258.

[28] R. Cobcroft, Literature review into mobile learning in the university context, Citeseer, 2006.

[29] C. Savill-Smith and P. Kent, The use of palmtop computers for learning: A review of the literature, Learning and Skills Development Agency, Regent Arcade House, 2003.

[30] S. Jun, et al., "A Context Model Based on Multi-agent in M-learning Environment," Proc. Edutainment 2007, LNCS 4469, 2007, pp.274-282. .

[31] S. R. Subramanya and B.K. Yi, "User Interfaces for Mobile Content," EEE Computer, Vol.39, No.4, 
2006, pp.85-87.

[32] B. Alexander, "Going nomadic: Mobile learning in higher education, " EDUCAUSE review, 2004.

[33] J. Colley and G. Stead, "Take a bite: Producing accessible learning materials for mobile devices," learning with mobile devices, pp.43.

[34] S. Fallahkhair, et al., "Dual device user interface design for ubiquitous language learning: Mobile phone and interactive television (iTV)," language teaching, Vol.8, No.9, pp.10-11.

[35] L. Uden, "Activity theory for designing mobile learning," International Journal of Mobile Learning and Organization, Vol.1, No.1, 2007, pp.81-102.

[36] R. Ting, Mobile learning: current trend and future challenges, Proc. IEEE International Conference on Advanced Learning, 2005.

[37] H. Ogata and Y. Yano, "How ubiquitous computing can support language learning," Proc. of KEST, 2003, pp.1-6.

[38] L. Motiwalla, "Mobile learning: A framework and evaluation," Computers \& education, Vol.49, No.3, 2007, pp.581-596.

[39] A. Danesh, et al., "Geney ${ }^{\mathrm{TM}}$ : Designing a collaborative activity for the palm ${ }^{\mathrm{TM}}$ handheld computer," ACM New York, NY, USA, 2001, pp.388-395.

[40] M. Ebner1, et al., "A Study on the Compatibility of Ubiquitous Learning (m-Learning) Systems at University Level,” Proc. HCII 2009, LNCS 5616, 2009, pp.34-43.

[41] D. Wiley, The instructional use of learning objects, Agency for Instructional Technology, Association for Educational Communications \& Technology, 2002.

[42] A. Holzinger, et al., "Mobile phones as a challenge for M-Learning: Examples for mobile interactive learning objects (MILOs)," Proc. Third IEEE International Conference on Pervasive Computing and Communications Workshops (PERCOMW'05), 2005, pp.307-311.

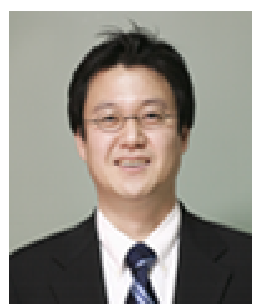

\section{Kwang Sik Chung}

Dr. Chung received B.S. degree, M.E. degree, and Ph.D. from Korea University, in 1993, 1995 and 2000, respectively. His major was distributed mobile computing. Currently he has interesting in M-learning and cloud computing for smart learning. $\mathrm{He}$ is an assistant professor at Korea National Open University.

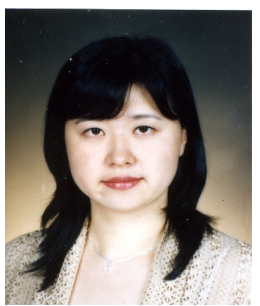

\section{Jeong Eun Lee}

She received B. S. degree in Educational Technology/Computer education and M. A. degree in Educational Technology from Hanyang University, Seoul, Korea, She is currently studying towards the Ph. D. degree in Educational Technology in Hanyang university. Her research interests include incorporating mobile and ubiquitous computing technology into learning environment design. 